\title{
Blood Money Currency Exchange Terminal
}

\section{Tooba Anwar}

University of Technology Sydney, Faculty of Arts and Social Sciences, PO Box 123, Ultimo NSW 2007, Australia.tooba.anwar@student.uts.edu.au

Blood Money Currency Exchange Terminal by artist, Ryan Presley, is an exhibition that displays Australian dollars notes appropriated and revamped to have Aboriginal warriors as the faces of currency. The large prints have taken about 2-3 months each to complete and are made with mixed classical mediums (watercolour and oil paint). This exhibition raised important queries, it raised the obvious point that why First Nations People's heroes are not on Australian currency, instead of those colonisers. First Nations People are rarely commemorated on money. The stories of poets, land rights pioneers and freedom fighters should be textbook history but unfortunately aren't something that we lean in our school curriculum. These pieces are important in the way that they subvert mainstream history and reach out beyond dead history to a living history.

There is great importance in unpacking a culture which has continued to exist in the face of unprecedented despotism. The exhibition itself is comprised of 6 notes. Next to each note is a biography of the subject of the dollar note and their tale of resistance. The 20-dollar note depicts Aboriginal warrior and fighter Woloa. Woloa's story is one of fierce resistance to the colonial regime, a regime that was so intimately violent with her, upon as a teenager she was abducted and enslaved where she was beaten, raped and tortured. During this time Woloa learnt to use English and firearms, in 1828 she broke free and stole many weapons. 


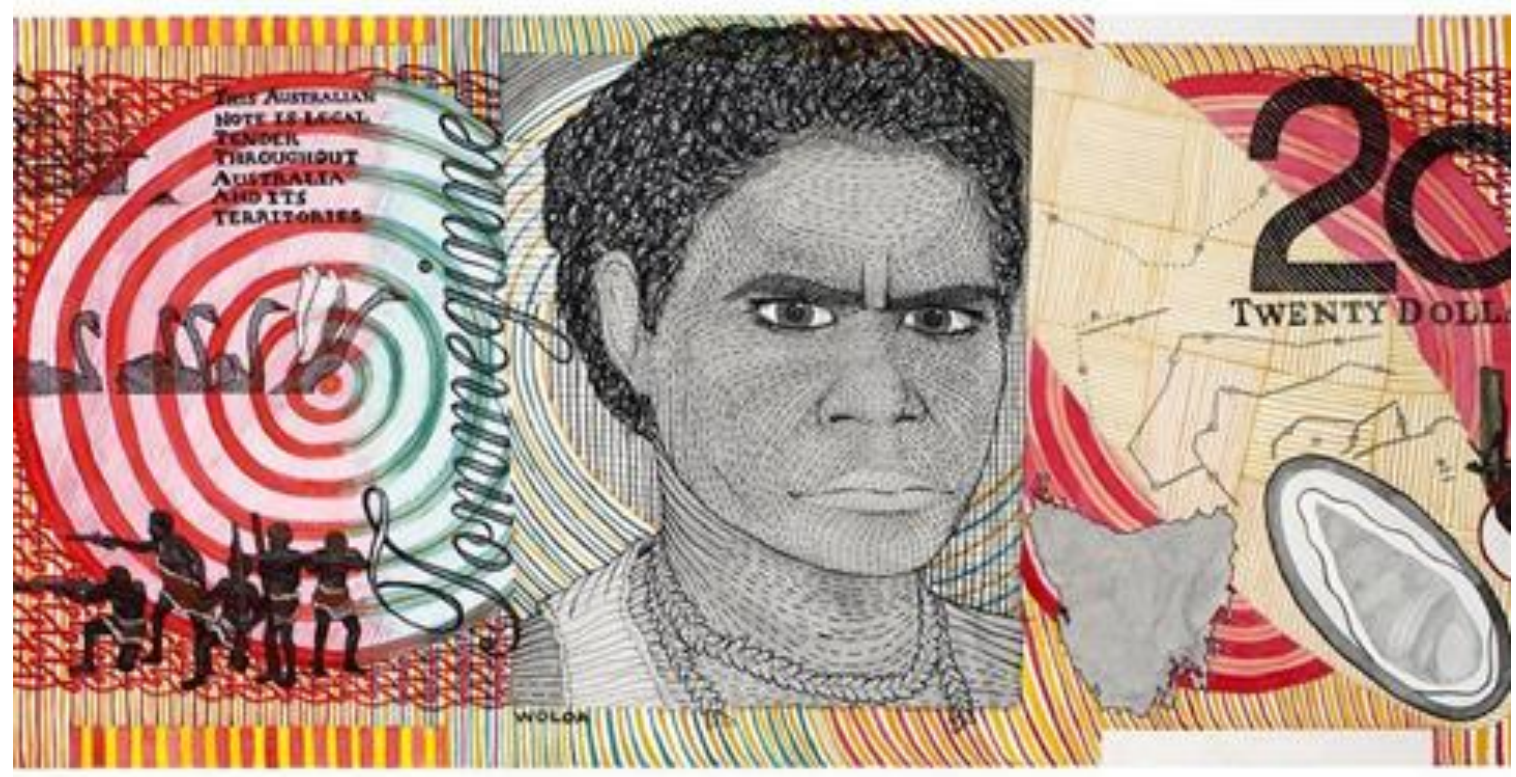

She went on to use her knowledge to lead many resistance fighters to attack and raid colonial settlements, earning her a reputation of 'The Amazon' among settlers at the time. Within the intricacies of the background pattern Presley has incorporated shells that would be used for Jewellery, Tomeginee woven textiles and Black swans which juxtapose European ships (which are sinking) and firearms. This gives a very real visual representation of the reality of the history wars.

Within this illustration of blood money wealth, it highlights the tale of resistance, and challenges the hegemony of invented Australian traditions; traditions that celebrate the Banjo Pattersons of previous times and the so-called Australian dream.

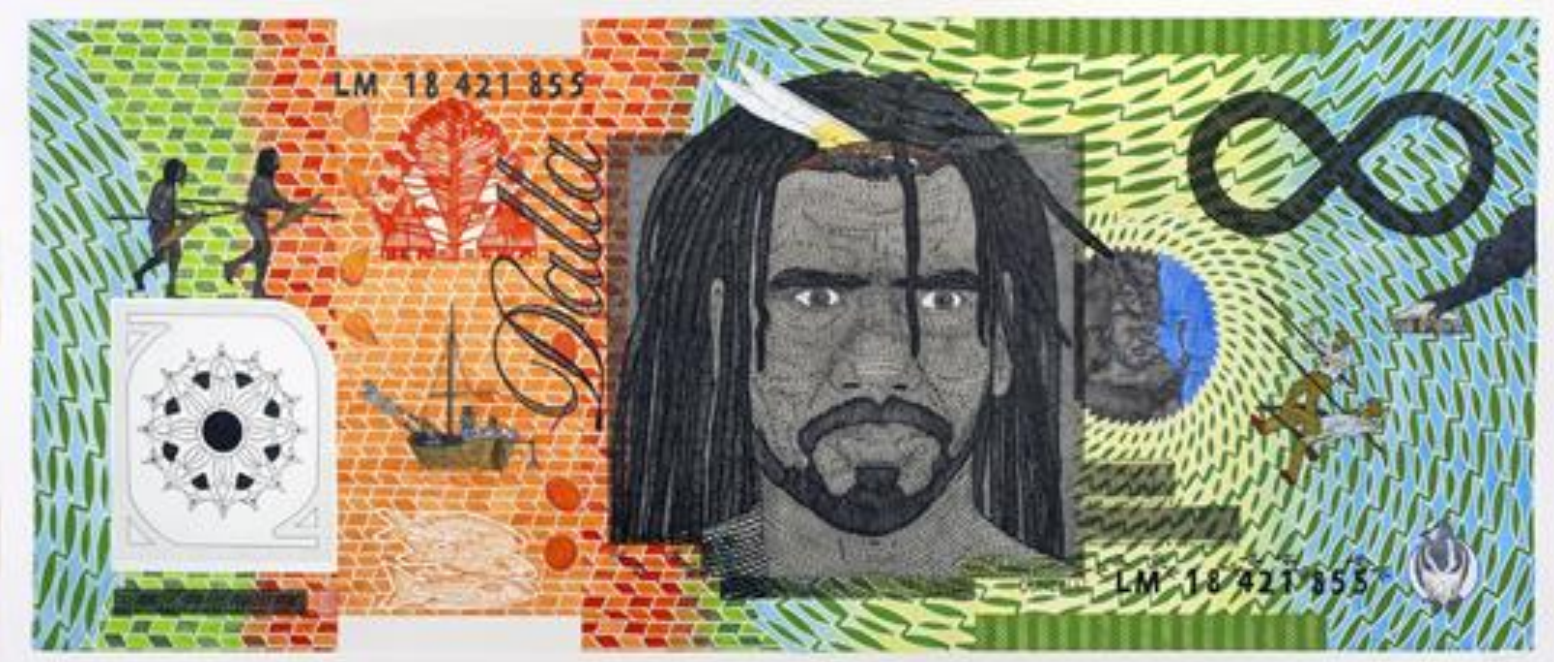

Depicted on the infinity dollar note is warrior Dundalli (1820-1855), who managed to avoid being captured for 14 years. The mythology behind him meant some saw him as a giant and some saw him existing as a spirit. Perhaps why Presley has selected that value, to link the 
transcending value of a spirit, and a number that also transcends this realm. Dundalli is living evidence to a force of resistance to be reckoned with, burning the Kilcoy station after an attack on the Dalla community where colonists had laced the people's flour with poison. As Gillen \& Ghosh show, depending on whether trade or settlement was the objective of the coloniser, the discursive practices changed (2007). At our current point in Australian history, we omit previous means of establishing our current state of settlement as a means of maintaining White Australian Traditions.

Presley contradicts the myth that we are fed, bringing fourth that all wealth and economic relations that exist today are founded on the systematic genocide of Aboriginal people. The history of the frontier massacres is evidence of the 'blood' that the 'wealth' of this nation is rooted in. Presley's dollar notes and artworks notably exemplify these warriors who have had to carry the burden of fighting back against a very real murderous state-sanctioned terror. A wave of terror that can be attributed for the 'eighty percent drop in Aboriginal Victorian population in fifteen years' (Ryan 2011). To ideologically justify ongoing political and economic relations that settlers were establishing Aborigines were demonised for living sustainably, maintaining the same culture and practice for thousands of years as well as public-shared ownership of land, food and shelter.

The resistance the First Nations People private-property centric living can be seen as the original communist menace (Wolfe 2006). The fixed, domesticated individuality of land corrupts the transience of being and the harmonious interactions between man and ecology as Rivers points out a communality of space and allowance for time-based use of spaces, as is mirrored in a living history approach, would allow for great dynamism to be realised within our current habitat (2019). However, this dynamism is precisely what must be destroyed in the pursuit of domestic colonial rule.

Analogous to the colonial expeditions in the Americas 'the Red Man's land would be mixed with Black Labour to produce white gold of the deep south' (Wolfe 2006). As Wolfe crudely outlines, primitive accumulation developing the base of American capitalism from the transAtlantic slave trade and murdering of First Nations People operate in a similar style to Australian capitalism as it launched itself by land stealing, exploitation of bonded labour in order to expand out onto the Pacific region. (Morris 1992) The most impactful part of the exhibition is the exchange terminal.

At the end point of the exhibition you can purchase a print of one of these notes; ranging from 10 dollars to 100 dollars, in the act of attaining some of the blood money you forfeit some Australian currency. This act between audience and exhibit, exchanging Australian money for blood money is quite a confronting experience. The audience is put in a position where they materially realise the social relations behind the wealth that they use every day. Money is not just a bit of paper worth something, it's a cog in a whole rapacious machine. The currency exchange rate is also subject to change, it changes every few hours, a man sits at the terminal to let you know that you can exchange by cash or card. The idea of this currency rate fluctuating is absurd and ironic. 
In a world of floating currency how does the pull and push of supply and demand determine the worth of blood money? The short answer is that the world doesn't because it can't, it doesn't look back, it doesn't slow down it keeps chugging away trying to find value in speculation and accumulation of more capital. No value is given to the living history of people. A history which would warrant we drastically change these sets of relations.

We are left tired and wanting to be able to use our bloody wealth through all our estranged exchanges, one begins to feel a profound desire not to participate in the onslaught. Upon exchanging at the terminal, we are informed that all money raised from these purchases goes towards funding an Aboriginal youth organisation, this offers a way out for the audience, providing a moment of redress.

The exhibition itself is something that provides a sobering truth of the reality of wealth in this country. Viewers learn about the hard war fought, but also are given hope in knowing that our actions can change the system we find ourselves in. Blood Money Currency Exchange Terminal is a glimpse into a living history, one which demystifies the brutality of Australian wealth but one that also celebrates the history and tradition of struggle First Nations People so valiantly fought in. It leaves us asking what we can exchange, absolving ourselves from compliance in the current running of things for a stance of hope in the future.

\section{References}

Presley, R. 2018-2019 Blood Money Currency Exchange Terminal, Mixed medium, watercolour and oil paint, Sydney, Museum of Contemporary Art.

Morris, B.1992, 'Frontier colonialism as a Culture of Terror', in Power, Knowledge and Aborigines, Bundoora, Vic., La Trobe University Press in association with the National Centre for Australian Studies, Monash University, pp 72-87.

Gillen, P. and Ghosh, D. 2007, 'Race' in Colonialism and Modernity, UNSW Press, pp 156177.

Ryan, L. 2012, 'Settler Massacres on the Australian Colonial Frontier, 1836-1851', in Dwyer, P.G. and Ryan, L. (eds), Theatres of Violence: War, massacre, mass killing and atrocity throughout history, New York, Berghahn Books, pp. 94-109.

Wolfe, P. 2006, "Settler Colonialism and the Elimination of the Native, Journal of GenocideResearch, 8:4, pp. 387-409.

Rivers, J. 2019, “Anti-Colonialism and Marxism” Medium Viewed June 2, 2019, <https://medium.com/@jaydenkaiorivers/anti-colonialism-and-marxism$9729 \mathrm{e} 6 \mathrm{fc} 76 \mathrm{~b} 1>$. 